\title{
Possibility of Dynamic Penetrometer Use in Clayey Sandy Soil on Railway Route Zenica- Sarajevo
}

\author{
Nedjo DJURIC ${ }^{\star}$, Dijana DJURIC, Dragan LUKIC
}

\begin{abstract}
Application of dynamic penetration is not widely spread, considering the limited number of data that can be obtained. When a larger number of boreholes on terrains built of soft rocks is required, there exists economic justification for the use of certain dynamic tests that can give data about resistance and soil density. Also, in parts where the access is difficult or impossible for the machines for soil probing, penetrometer tests are only possible for obtaining certain parameters. Correlation between point of resistance and shear strength can obtain data of undrained firmness shear strengths for clayey soils, and based on the value of point of resistance the percentage of compaction of soil with quite real accuracy. The dynamic penetration test was applied along the route of the Zenica-Sarajevo railway. Since this is a rarely used type of research, the authors hope that this paper will serve to others as well, towards further research on better correlations between the two types of methods. It is necessary to make the method with penetration as applicable as possible, because it can be used in very inaccessible places with many more test points and does not require large financial investments.
\end{abstract}

Keywords: claysoils; dynamic probing; point of resistance; shear strength

\section{INTRODUCTION}

In conditions when it is not possibile to completely research the terrain with drilling, the method of dynamic sounding with certain penetrometers can be applied. On inaccessible parts of the railway route Zenica-Sarajevo a method of sounding with dynamic penetrometer-medium (DPM) was applied for research drilling. In clayey and sandy sediments 42 tests were done from which tests in clays were correlated with the values of laboratory tests of clay samples that were taken from research trial pits till the depth of 3,0 m. Other data obtained in sandy sediments were treated with the application of appropriate equation. Obtained information about firmness and density of layers can be observed as relative and can be correlated with the same data obtained in research works.

This type of research is very rare in Bosnia and Herzegovina, as well as in Europe. This method was applied for the first time in this area by researching the Corridor Vc highway on the Svilaj-Doboj route [1]. The results of the research were reliable, which provided the basis for application in the research of the route of the railway Zenica-Sarajevo.

Dynamic Penetrometer Test (DPM) is favorable for detection of soft clay and sand layers. Interpretation of test results demanded a complete evaluation of test conditions and limitations of test procedures. The test is performed through soft layers till the depth of a thicker layer, when further cone penetration is stopped.

\section{RESEARCH METHODOLOGY}

Researched railway route on the length of around 50,0 $\mathrm{km}$ passes through the valley od the river Bosna. It is located in the central, closer to the east, part of Bosnia and Herzegovina, on the territory of the Federation of Bosnia and Herzegovina entity. It passes through several municipalities: Zenica, Kakanj, Vareš, Breza, Ilijaš, Vogošća and Sarajevo.

The terrain is built of alluvial sediments of decomposed debris, clay, sandy clay and sand, and substrate depending on terrain morphology of gravel, marl and limestone of different age (Fig. 1).

Thickness of sediments of decomposed debris is up to $0,4 \mathrm{~m}$, and is often mixed with deposited materials. Lower part of the terrain is clay, which is in certain intervals partially sandy. It is a dominant member of fine grained fraction of alluvial sediments of the river Bosna. It represents soft clays. Under them is a sand layer of fine grained fraction that gradually passes into gravel.

On inaccessible parts of the terrain for research drilling, the method of dynamic sounding was applied, or investigation of specific soil resistance on cone penetration. The test was performed next to the embankment of railway track in the natural soil.

Selected method Dynamic Penetration Test - medium (DPM) was accepted as part of the proposition for standardization of Penetration Tests for use in Europe (ISSMFE 1977 and 1988), and was standardized in Great Britain (BS 1377: part 9, clause 3.2), Germany (DIN 4094, part 1 and 2) and ISO 22476-2 [2-4].

Advantage of the method on researched terrain is accessibility of location, work speed; it is economically acceptable, it can separate cohesive layers from unbounded soil and give data based on which a vertical profile of the terrain can be made.

The method covers assessment of soil and soft rocks resistance in relation to dynamic penetration of cone. Load as a weight of certain mass and height of fall are used for guiding of cone. Resistance of cone penetration is defined as the number of strokes that is necessary for performance of penetrometer till a certain depth [5]. Continuous record is enabled with depth progress of cone.

Characteristics of parameter are the following:

- Hammer mass / kg: $30 \pm 0,3$

- Height of fall / mm: $500 \pm 10$

- $\quad$ Length/diameter $\left(D_{n}\right)$ ratio: $\geq 1 \leq 2$

- $\quad$ Mass of anvil and guide rod, max. / kg: 18

- $\quad$ Cone apex angle, deg.: $90^{\circ}$

- $\quad$ Cone base area $A / \mathrm{cm}^{2}: 10$

- $\quad$ Cone base diameter $D / \mathrm{mm}: 35,7 \pm 0,3$

- $\quad$ Cone base diameter, wom-min. / mm: 34 
- $\quad$ Cone mantle length / $\mathrm{mm}: 35,7 \pm 1$

- $\quad$ Cone taper angle, upper, Deg.: 11

- $\quad$ Length of cone, tip / $\mathrm{mm}: 17,9 \pm 0,1$

- $\quad$ Rod mass, max. $/ \mathrm{kg} / \mathrm{m}: 6$

- $\quad$ Rod diameter, max. / mm: $32 \pm 0,2$

- $\quad$ No. of strokes per $x / \mathrm{mm}: N_{10}: 100$
- $\quad$ Standard range of strokes: 3 - 50

- Rod deviation:

○ lowermost 5,0 m (\%): 0,1

○ remainder (\%): 0,2

- Specific work per stroke $\mathrm{mgh} / \mathrm{A}$ in $\mathrm{kJ} / \mathrm{m}^{2}: 150$

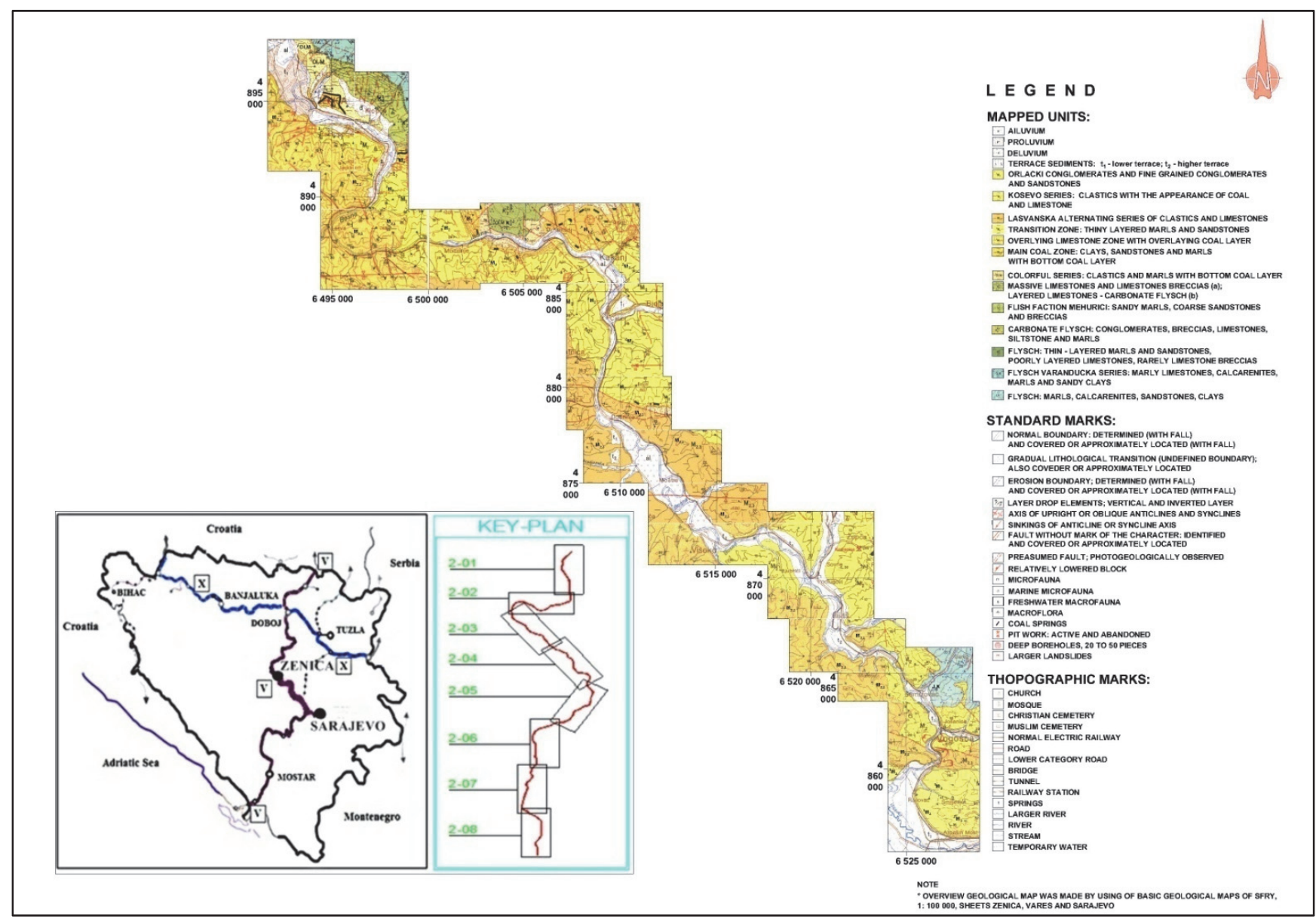

Figure 1 Geological map of the researched area, railway route Zenica-Sarajevo

During test performing it is important to maintain continuity of cone penetration into the soil. Number of strokes is from $15-30$ in a minute, except at sand where it can increase up to 60 strokes/minute. Continuity of strokes is best reflected at penetrometers on motor drive. For reduced effect of friction, piles are rotated by $1 \frac{1 / 2}{2}$ circle on every $1,0 \mathrm{~m}$. Rotation of piles was done with wrench, capacity $>200 \mathrm{Nm}$, graduations $<5 \mathrm{Nm}$. Reduction of friction can be achieved by throwing of drilling mud or water in perforated part of the pile close to the cone. Friction cannot be removed completely, but it can be minimized [6-9].

Interpretation of results was done with the help of Dutch equitation [10] where a point of resistance $\left(q_{d}\right)$ was determined at constant stroke acceleration [7]:

$q_{d}=\frac{m}{m+m_{1}} r_{d} ; r_{d}=\frac{m g h}{A e}$

where: $r_{d}$ - point resistance / $\mathrm{Pa}$,

$m$ - weight mass $/ \mathrm{kg}$,

$m_{1}$ - total extended pile, anvil and pile guide mass / kg $g$ - acceleration due to gravity $\left(9,81 \mathrm{~m} / \mathrm{sec}^{2}\right)$

$h$ - height of weight fall / $\mathrm{m}$

$A$ - area at the base of the cone $/ \mathrm{m}^{2}$

$e$ - average penetration in m per stroke $\left(0,1 / N_{10}\right)$

$N$ - number of strokes per penetration: $100 \mathrm{~mm}$

Value $r_{d}$ is an evaluation of work during cone penetration in the soil. Value $q_{d}$ changes $r_{d}$ and should take into consideration the inertia driving rod and weight after stroke with the anvil for different type of equipment [6]. Butcher et al. (1996) showed that dynamic tests are characterized with similar values of $q_{d}$ for different types of equipment in same clay layer. For determination of undrained shear strength $c_{u}(\mathrm{kPa})$ the following equations are given:

- softclay:

$c_{u}=\frac{q_{d}}{170}+20 ; c_{u}<50 \mathrm{kPa}$

Butcheretal. (1995).

- hard clay: 
$c_{u}=\frac{q_{d}}{22} ; c_{u} \geq 50 \mathrm{kPa}$

Butcheretal. (1995)

- clay:

$c_{u}=0,455 \frac{q_{d}}{s_{t}}+10$

Butcheretal. (1995)

- clay:

$c_{u}=\frac{q_{d}}{20}$

Langton (2000)

Above equations are in wide range for which can be given different coefficients for different locations and equipment. Butcher et al. (1996) suggested equations for all types of clay [6]. Langton (2000) observed clay as a compact soil and gave his equation [11].

Correlation of the Eq. (1) is given also through the evaluation of dynamic resistance on cone penetration Rpd over Olandesi formula [12]:

$R_{p d}=\frac{M_{1}^{2} H}{A e\left(M_{1}+M_{2}\right)}=\frac{M_{1}^{2} H N}{A \delta\left(M_{1}+M_{2}\right)}, \frac{\mathrm{kg}}{\mathrm{cm}^{2}}$

where:

$R_{p d}$ - dynamic cone penetration resistance $/ \mathrm{kg} / \mathrm{cm}^{2}$

$M_{1}$ - weight mass $30 \mathrm{~kg}$

$M_{2}$ - total pile, anvil and extension mass / $\mathrm{kg}$

$N$ - number of strokes of dynamic penetrator on $10 \mathrm{~cm}$

$H$ - height of weight fall $(50 \mathrm{~cm})$

$A$ - cone surface $/ \mathrm{cm}^{2}$

$\delta$ - one measuring interval $10 \mathrm{~cm}$

$e$ - value of decay for one (1) blow, $e=\delta / N$

This formula gives possibility of transferring the strokes energy of weight $Q_{\mathrm{DPM}}$ into $Q_{\mathrm{SPT}}$, whereby is obtained theoretical coefficient of energy $\beta$. Weight mass SPT is $63,5 \mathrm{~kg}$, and height of the fall is $76,3 \mathrm{~cm}$.

$$
Q_{\mathrm{DPM}} \text { i } Q_{\mathrm{STP}}=\frac{M_{1}^{2} H}{A \delta}\left(\frac{\mathrm{kg}}{\mathrm{cm}^{2}}\right) ; \beta=\frac{Q_{\mathrm{DPM}}}{Q_{\mathrm{STP}}} ; N_{\mathrm{STP}}=\beta N
$$

Other SPT characteristics are the following:

- $\quad$ Diameter of hammer, $D_{h} / \mathrm{mm}$ : 180

- $\quad$ Diameter of hammer guide rod / mm: 40,5

- $\quad$ Diameter of anvil, $D_{a} / \mathrm{mm}: 71$

- Diameter Cone / mm: 50

- $\quad$ Area of cone $A / \mathrm{cm}^{2}: 19,6$

- $\quad$ Penetration length for counting stroke numbers $L$ /m: 0,3

- Specific work per stroke $\mathrm{mgh} / \mathrm{A}$ in $\mathrm{kJ} / \mathrm{m}^{2}: 229$

\section{RESEARCH RESULTS}

Tests were performed to the depth of $5,00 \mathrm{~m}$ or to a depth at which soil resistance goes over the engaged penetrator force $(>50$ strokes $/ 10,0 \mathrm{~cm})$. In situations when during test experiment at a certain depth was not achieved rod - cone penetration of $10,0 \mathrm{~cm}$ after fifty (50) weight strokes, additional series of fifty (50) strokes was performed, and if even then was not achieved progresscone penetration for interval $\delta=10 \mathrm{~cm}$ in terrain records was inscribed number of ninety-nine (99) weight strokes and the test was aborted. At very soft clays cone resistance was low, so depth of cone penetration was recorded by stroke and those data were not taken for processing.

Research trial pits were done to a depth of 3,0 m in parts of the terrain that were accessible. They were not close to DPM tests, but were related for the same layers on terrain (clays, clayey sand and sand). Mapping of open profile of trial pit and the use of data from Basic geological map introduced the character of sediments that build terrain along the railway route.

\subsection{Use of Dutch Equitation}

Layers of clay, clayey sand and sand were analyzed based on the number of strokes of weight with the depth (Fig. 2). In sand layer was recorded partial decay because of different compactness, while clay layer characterized soft clays with average number of strokes 10 per interval of $10 \mathrm{~cm}$. Values $q_{d}$ follow legality of strokes number with depth of layers, (Fig. 2).

Determination of undrained strength $c_{u}$ was done according to Eq. (2) for soft clays and is shown on diagram, (Fig. 3).

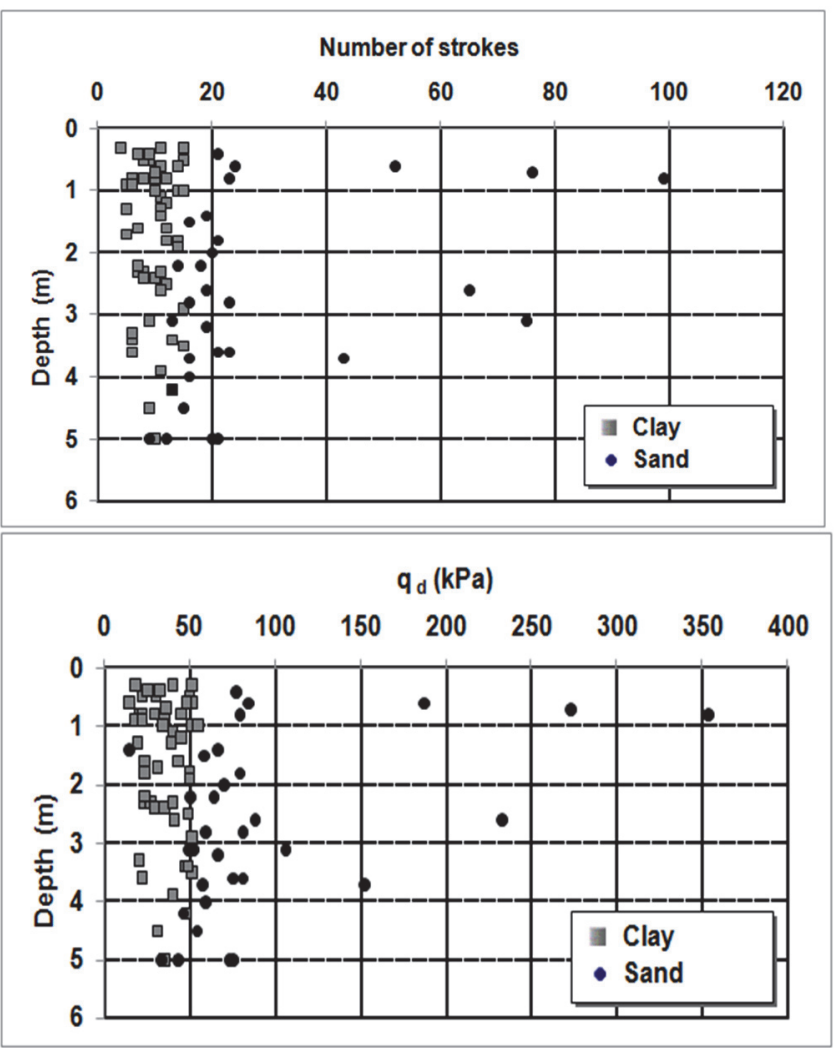

Figure 2 Number of weight strokes (left) and values of dynamic resistance point $q_{d}$ (right) in different layers 
Characteristic is a linear dependence of dynamic soil resistance $q_{d}$ and undrained shear strength $c_{u}$, considering it is about soft clays that are in near surface part of the terrain. Đurić N. et al. conducted several hundreds of $D M P$ tests in 2012 on highway route of corridor Vc that passes with great part through the river Bosna valley in Bosnia and Herzegovina. They correlated them with Eq. (2) and Eq. (3) of Butchera et al: 1995 [1]. Results sufficiently corresponded to the laboratory test results on samples taken from research trial pits and trenches. Setting the correlation between $q_{d}$ and $c_{u}$ can be obtained data of undrained firmness for clayey soils $c_{u}$ with almost real accuracy.

Values $c_{u}$ obtained according to Eq. (2) are set in relation to cohesion $c$, obtained in laboratory on Shear test, (Fig. 3). Samples were taken from research trial pits. Results obtained with Shear test show lower values. They do not maintain the same depth of testing or close location, but characterize the same clayey layer equal with grain size composition of clay and state of consistency. Conducted correlation gives justification to dynamic resistance of soil testing with DPM method, because data are sufficiently reliable for use.
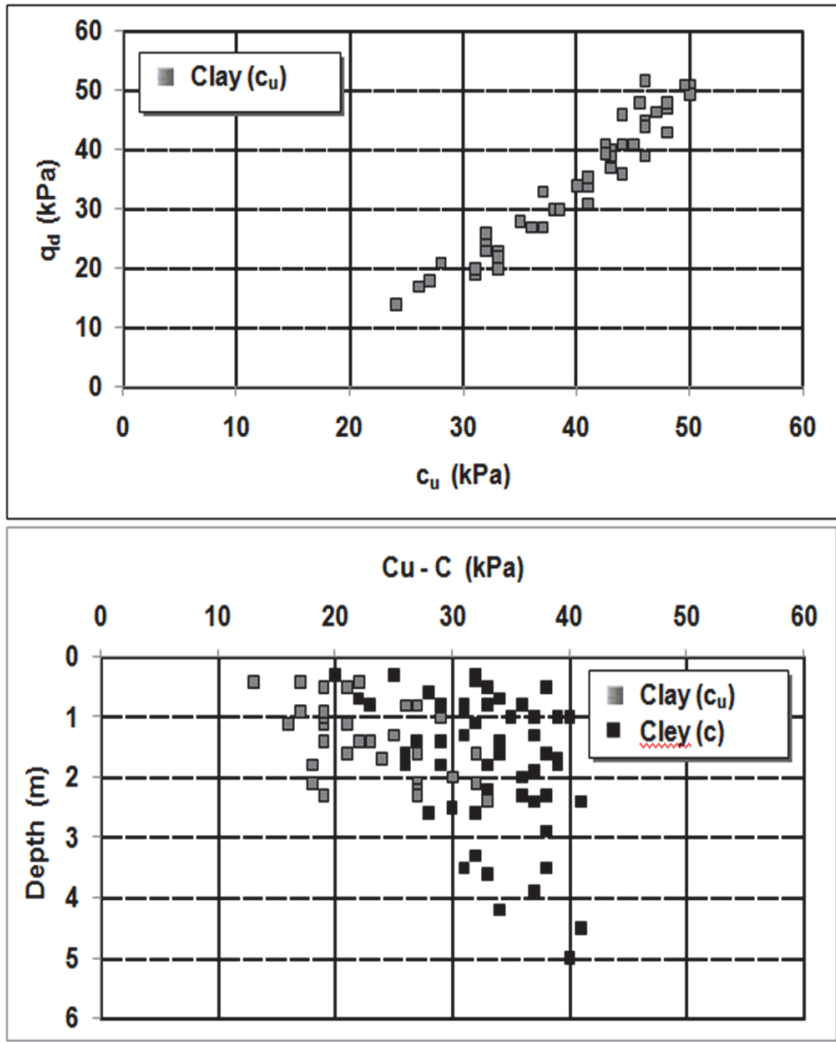

Figure 3 Relation of dynamic resistance point $q_{d}$ and undrained firmness $c_{u}$ (left) and relation of undrained firmness $c_{u}-c$ (right) in clay layer

Based on the value $\mathrm{q}_{\mathrm{d}}$ was determined the percentage of soil compaction $C P$ according to the form:

$C P=\left(16,454 q_{d}\right)^{0,193}$

Dynamic resistance of cone was taken for different configurations of DPM, and correlations between cone resistance and percentage of compactness are given in Fig. 4. Compactness of clay layer ranges from $3,0-3,75 \%$, and of sand layer $3,6-4,2 \%$. It can be concluded that those are well compacted layers that are placed under the base of railway route.

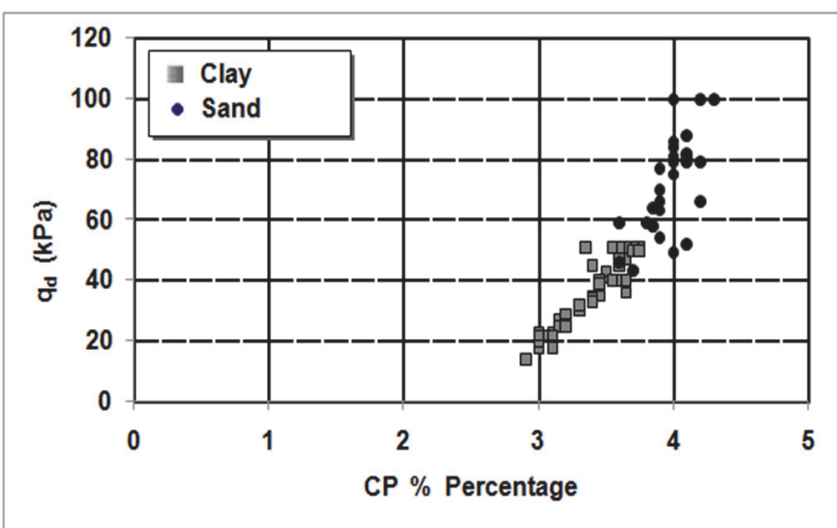

Figure 4 Correlations between $q_{d}$ and $\mathrm{CP}$ in different layers

With the use of Eq. (8) from which we determine percentage of compactness $C P$ we obtain reliable data, considering that $q_{d}$ can be used for different configurations DPM [13, 14]. Evaluation of compactness percentage CP is acceptable and can be used on terrains that are built from clay sediments, clayey sand and sand.

\subsection{Use of Olandesi Equation}

Determination of dynamic resistance depending on number of weight strokes, by Olandesi equation is given in diagram (Fig. 5), according to the standard EN ISO 224762, 2008 [15].
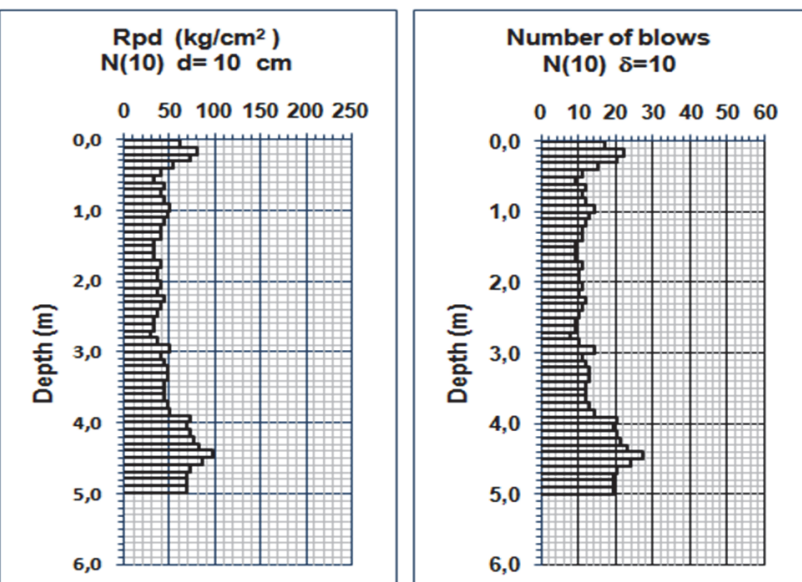

Figure 5 Test of Dynamic Penetration - Diagram of Dynamic Resistance (Research trial pit $N_{0} 43$ )

Lithological composition:

$$
\begin{array}{cl}
0,00-3,10 & - \text { Alluvial sediments (al) } \\
& - \text { Clay, Clay-Sand } \\
& -\gamma=19.6 \mathrm{kN} / \mathrm{m}^{3} \\
& -\varphi=17^{0} \\
& -\mathrm{c}=20 \mathrm{kPa} \\
3,10-5,00 \quad-\text { Alluvial sediments (al) } & \text { - Sand, occasionally with clay } \\
\text { interlayers } & -\gamma=19.2 \mathrm{kN} / \mathrm{m}^{3} \\
& -\varphi=28^{0} \\
& -\mathrm{c}=12 \mathrm{kPa}
\end{array}
$$


In general, along the railway route are present alluvial sediments where it is very hard to separate layers of clay from sand. Those are mostly clayey sandy sediments with occasionally clearly expressed layers of clay and sand. On parts of the route where muddy sediments are present, fast cone penetration and small number of weight strokes were registered. Their values were not analyzed in the work, but served for geological interpretation of the terrain profile.

Dynamic resistance $R_{p d}$ showed continuous schedule of weight strokes in well consolidated soil to $5,0 \mathrm{~m}$. Besides determination of $R_{p d}$ based on number of strokes $N$ $=N_{(10)}$, can also be determined dependence of $R_{p d}$ on pile resistance, that rotate on every 1,0 for $1 \frac{1}{2} 2$ circle. Pile resistance is registered at the end of every interval of $1,0 \mathrm{~m}$, in order to separate cone penetration resistance from the resistance that is shown during the passing of stroke piles through soil. Based on the value of dynamic resistance $R_{p d}$ can be determined other important parameters. So Cope (2011) gave opportunity for determination of the number of strokes of standard penetration test over resistance $R_{p d}$ according to the following Eq. (9) [16]:

$$
\left(N_{1}\right)_{60} \approx 2,4 R_{p d}
$$

Index of relative compactness [17] can be determined according to the equitation:

$$
D_{r}=100 \sqrt{\left(N_{1}\right)_{60} / 60}
$$

Dependence of the index of relative compactness on the number of strokes for sand layer is given in Fig. 6 . Obtained values $D_{r}$ are acceptable and give real data for sand sediments.

In sandy sediments number of strokes for cone penetration is smaller under the level of underground waters, especially in conditions with small number of strokes measured. Correlation is done by European standards EN ISO 22476-2, 2008.

Translating DPM test into SPT test according to Eq. (7) gives a possibility for determination of angle of internal friction, or direct establishment of dependence between penetration resistance and angle of shear resistance [18-25] While conducting SPT test in sands Skempton (1986) suggested that the number of strokes of weight $\mathrm{N}$ is reduced to $60 \%$ [19]. Correlation only with vertical voltage is for normal consolidated soil, while for over consolidated soils it is necessary to do correlations with horizontal voltage that is characteristic for beginning penetration resistance. Values of SPT obtained with Eq. (7) are shown in Fig. 6.

Angle of shear resistance depends on relative compactness and level of normal voltages on research location. Relative compactness is directly reflected in results of penetration research. Establishment of dependence between results of SPT tests obtained with Eq. (7) and relative compactness $D_{r}$ given by Gibbs-Holtz (1957) [26] and (1979) [27] is shown in Fig. 7. Haldar and Tang approximation of Gibbs and Holtz equation for correlation of compactness (1979) is given in the form of Eq. (11), [27]:

$$
D_{r}=\left(\frac{N}{0,21 p_{0}^{\prime}+20}\right)^{0,5} \times 100 / \%
$$
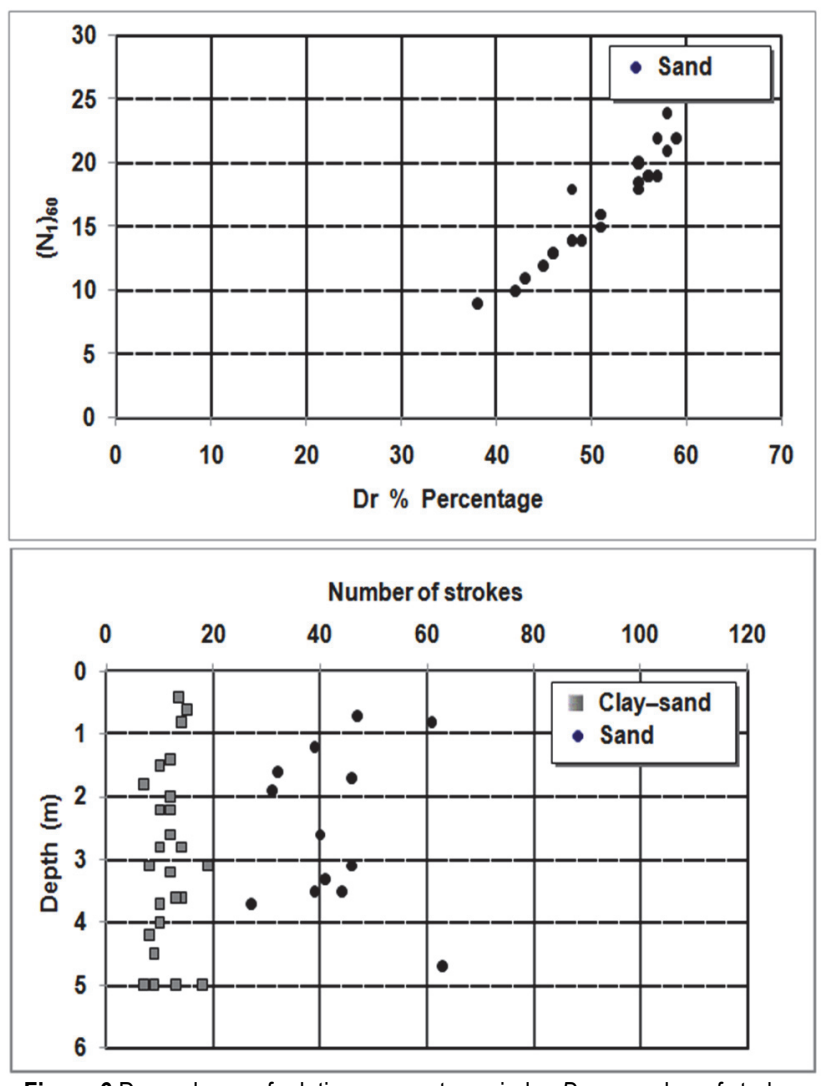

Figure 6 Dependence of relative compactness index $D_{r}$ on number of strokes $\left(N_{1}\right)_{60}$ in sand layer (left) and number of strokes $N_{\text {SPT }}$ in clayey sand and sand layers (right)

Schmertmann (1975) gave connection between results of standard penetration test $N$ and angle of shearing resistance for sands, Fig. 6, [28], approximated from Kulhawy and Mayne (1990) over the form [29]:

$\varphi=\operatorname{arctang}\left[N /\left(12,2+20,3 \frac{p_{0}^{\prime}}{p_{a}}\right)\right]^{0,34}$

where:

$p_{0}{ }^{\prime}$ - beginning vertical effective voltage in terrain $/ \mathrm{kPa}$

$p_{a}$ - active pressure of soil / $\mathrm{kPa}$

Based on obtained values of SPT tests from Eq. (7) and with the use of Gibbs-Holtz and Schmertmann diagram were determined the values of relative compactness and angle of shear resistance in clay sand and sand layers, Fig. 7.

Values in Fig. 7 relate to consolidated soils, correlated with vertical voltage. Relative compactness fits to data obtained on terrain during mapping of research works. It is about compact to very compact sediments in conditions without presence of water, while in water presence their values are worse. Angle of shear resistance showed a bit bigger results, which is a reality for compact sands. 

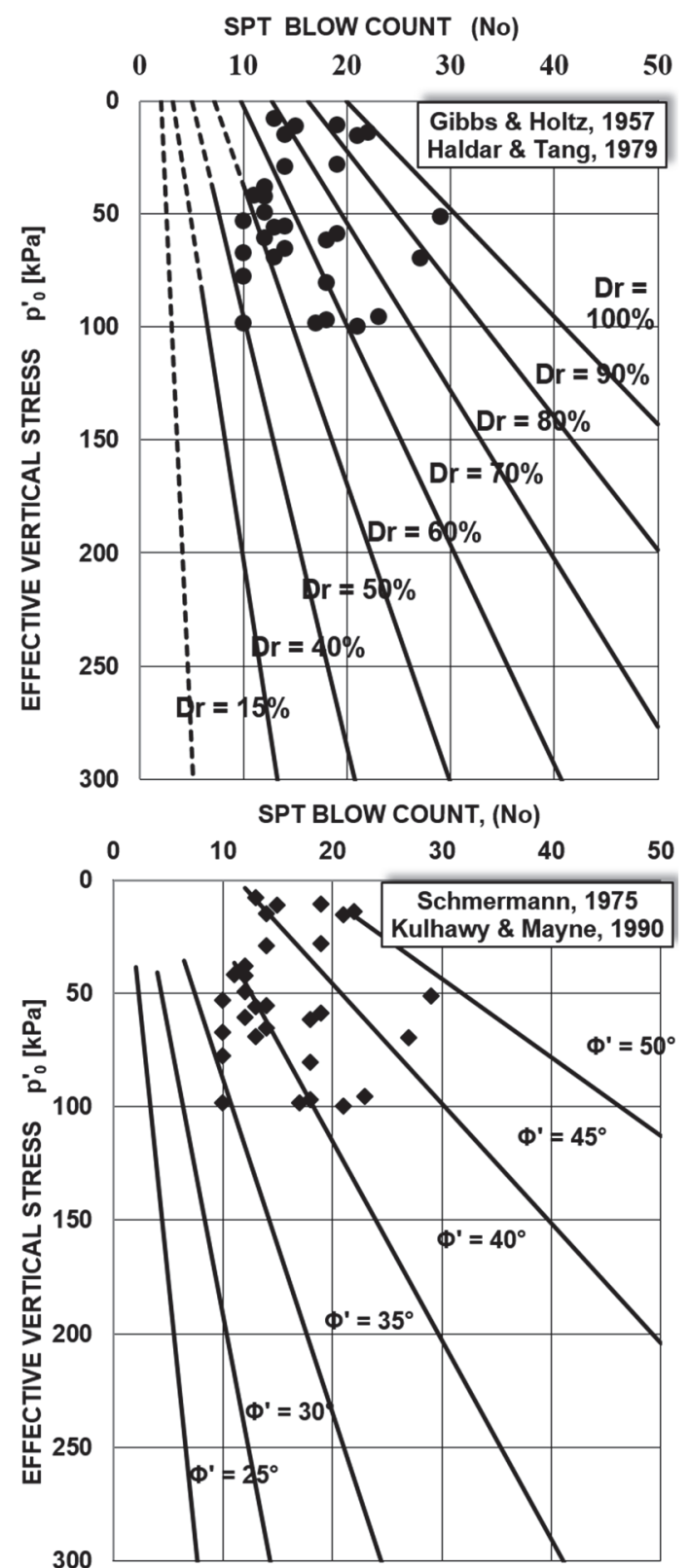

Figure 7 Relative compactness and angle of shear of sand resistance in dependence on SPT

\subsection{Discussion}

With the use of terrain data obtained during terrain research with Dynamic Cone Penetrometer (DPM) and research trial pits, together with data of Basic geological map was constructed geological map of the terrain along the railway route Zenica-Sarajevo. Data obtained with DPM tests made it possible to determine values of undrained cohesion relative compactness and angle of shear resistance by applying certain empirical equitations. The equations of several authors were used, and obtained values are real and fit to characteristics of the terrain, that are geologically well examined during terrain research.

Lithological structure of researched terrain has continuity of alluvial sediments, but within this package sediments change in vertical and horizontal direction, so it is hard to separate clay layer from sand layer. Mostly those are clayey sandy sediments with periodic presence of clay and sand layers. Geologically all can be observed as one layer, separated as fiction of clayey-sandy sediments. Because of that occur periodically different values of parameters by depth. Somewhere sand is closer to the terrain surface, and clay is deeper.

The use of Dutch equitation determined dynamic resistance in soil point $q_{d}$, based on which were determined values of undrained firmness $c_{u}$ and soil compactness $C P$. For soft clays undrained shear firmness $c_{u}$ is correlated with results obtained on Shear test in laboratory. It shows continuity of test results, where there are no data wasting, and increased values of $c_{u}$ are in acceptable limits. Evaluation of compactness percentage is acceptable.

The use of Olandese equitation determined the value of dynamic resistance $R_{p d}$, based on which were obtained values of Standard penetration test SPT and index of relative compactness. With the data of Standard penetration test SPT, was established dependence between penetration resistance and angle of shear resistance that depends on relative compactness. For consolidated soil and vertical voltage, correlation gives reliable data in clay sand and sand sediments.

\section{CONCLUSION}

The work presents the use of the Dynamic Cone Penetrometer (DPM) method on railway route that passes through terrains of complex geological structure and morphological characteristics. Two equitations were used, based on which it was able to obtain necessary data about geomechanical characteristics of the soil. They showed that terrain data can be used with sufficient accuracy for determining the resistance point $\mathrm{q}_{\mathrm{d}}$, undrained cohesion $\mathrm{Cu}$ and soil compactness $D_{r}$.

Correlation of undrained cohesion $c_{u}$ with results obtained in Shear test is satisfactory. Percentage of soil compactness $C P$ of clay layer ranges from 3,0 - 3,75\%, and of sand layer from 3,6-4,2\%, which shows that those are well compacted layers. Translating data of DPM tests into SPT tests with the use of equations Gibbs-Holtz and Schmertmann, were determined values of relative compactness and angle of shear firmness.

Besides the research on railway route the DPM method was used on highway route of corridor $\mathrm{Vc}$ that passes through almost same terrains, parallel to railway. This showed that the method was favorable for soil research on inaccessible terrains and on terrains where there can be a reduced number of research works with boreholes. In those cases correlation of DPM and SPT data of research boreholes have larger reliability.

\section{Acknowledgement}

This paper was realized within "European Union's 2008 IPA Programme for Albania, Bosnia and Herzegovina, Croatia, The Former Yugoslav Republic of Makedonia, Montenegro, Serbia, Kosovo*, Turkey and Iceland"-Infrastructure Projects Facility Technical Assistance Window (IPF TA) Western Balkans, Europe Aid/128073/CSER/MULTI. Project: WB5-BiH-TRA-14. 


\section{REFERENCES}

[1] Đurić, N. \& al. (2012). CoridorVc, Motorway, Main Desing, Section Svilaj-Doboj South (Karuse), around $63 \mathrm{~km}$ long. Library of the Technical Institute, 35-A/2012.

[2] British Standards Institution. (1999). Code of Practice for Site Investigations. BS 5930, 1-12

[3] Deutsches Institut fur Normung. (1974). Dynamic and static penetrometers, Dimensions of apparatus and method of operation. DIN 4094, e . V.Berlin

[4] ISO 22476-2. (2005). Geotechnical investigation and testing, FieldTesting, Part 2: Dynamic probing. Case postal 56, CH1211 Geneva 20

[5] Tecnotest, Solilpenetrometers 8.1. Light-weight Motorized Dinamic Penetrometers. Tecnotest manufacturers the model $\mathrm{TP} 223 / \mathrm{S}$.

[6] Butcher, A. P., McElmeel K., \& Powell J. J. M. (1996). Dynamicprobinganditsuse in claysoil. Proceedings of the Internaional Conference on Advances in Site Investigation Practice, 383-395. ICE London, Thomas Telford

[7] Michi, Y., Matsumoto, T., Ishihara, S., \& Shirai, N. (2004). Application of dynamic portable cone penetration tests to quality assessment of improved soil. Proceedings, Seventh International Conference on the Application of Stress-Wave Theory to Piles, 333-340. Kuala Lumpur

[8] Card, G. B., Roche, D. P.\&Herbert, S. M. (1990). Application of Continuous Dynamic Probing in Ground Investigation, Field testing in Engineering Geology. GeologicalSocietyEngineeringGeologySpecialPublication, 6. 129-135. https://doi.org/10.1144/GSL.ENG.1990.006.01.14

[9] Hatanaka, M. \& Uchida, A. (1996). Empirical correction between penetration resistance and effective friction of sandy soil. Soils \& Foundations, 36(4), 1-9, Japanese Geotechnical Society. https://doi.org/10.3208/sandf.36.4_1

[10] Cassn, M. (1956). Lesessays in situ enmechaniquedessols. Realisation et interpretation, "Eyrolles, 1, 146-161.

[11] Langton, D. D. (2000). The panda light-weight penetrometer for soil investigation and monitoring mateial compacton, Soil Solution Ltd, 8 Marlowecourt, Macclsfield, Cheshire, SK118AY

[12] ISSMFE. (1988). Classificazionedei penetrometri dinamici, tipo Medio (DPM).

[13] Khodaparast, M., Rajabi, M., \& Mohammadi M. (2015). Thenewempirical formula based on dynamicprobing test results in fine cohesivesoils. Geotechnique, International Journal of Civil Engineering, 13(2), 105-113. https://doi.org/10.22068//JCE.13.2.105

[14] Tatsunori, M., Phan L. T., Akihiko, O., \& Shinya, S. (2015). Measurements of driving energy SPT and various dynamicc one penetration tests. The Japanese geotechnical Society, Soiland Foundations, 201-212. https://doi.org/10.1016/j.sandf.2014.12.016

[15] EN ISO 22476-2. (2008). Geotechnical Investigation and Testing -Field Testing-Part 2: Dynamic Probing.

[16] Cope, M. (2011). Dinamic probe theory revisited-effective interpretation of dynamic test results. Formerlyof Geotek Services Limited, Aucland New Zeland

[17] Terzaghy, K. \& Peck, R. B. (1948). Soil Mechanics in Engineering Practice. 1st Edition John WileyandSons. New York.

[18] Riggs, C. O. (1986). North American Standard Penetration Test practice. An essay: in Use of Insitu Tests in Geotechnical Engineering. ASCE Geotechnical Special Publication, 6.

[19] Skempton, A. W. (1986). Standard Penetration Test Procedures and the Effects in Sands of Overburden Pressure, Relative Density, Particle Size, Aging and Overconsolidation.Geotechnique, 36(3), 425-447.

https://doi.org/10.1680/geot.1986.36.3.425
[20] Liao, S. \& Whitman R. (1986). Overburden Correction Factors for SPT in Sand. Journal of Geotechnical Engineering, 112, 373-377 https://doi.org/10.1061/(ASCE)0733-9410(1986)112:3(373)

[21]Clayton, C. R. I. (1990). SPT Energy Transmission: Theory, Measurement, and Significance. Ground Engineering, 23(10), 35-43.

[22] Yokel, F. Y. (1982). Energy transfer in standard penetration test. Journal of Geotechnical Engineering, 108(9), 11971202.

[23] Morgano, C. M. \& Liang, R. (1992). Energy transfer in SPTRod length effect. Proceedings of the Fourth International Conference on the Application of Stress-Wave Theoryto Piles, 121-127. Rotterdam.

[24] Robertson, P. K., Woeller, D. J., \& Addo, K. O. (1992). Standard penetration test energy measurements using a system based on a personal computer. Canadian Geotechnical Journal, 29, 551-557. https://doi.org/10.1139/t92-062

[25] Schmertmann, J. H. \& Palacios, A. (1979). Energydynamics of SPT. Journal of Geotechnical Engineering, 105(8), 909926.

[26] Gibbs, H. J. \& Holtz, W. G. (1957). Research on determining the density of sand by spoon penetration tests. Proceedings of the $4^{\text {th }}$ Internacional Conference on Soil Mechanics and Foundation Engineering., 1, 35-39.

[27] Haldar, A. \& Tang, W. H. (1979). Uncertainty analysis of relative density. Journal of Geotechnical Engineering, 107(7), 899-904.

[28] Schmertmann, J. H. (1975). Measurement of in situ shear strength, keynote lecture. Proceedings of the conference on in-situ measurement of soil properties, II. American Society of Civil Engineers.

[29] Kulhawy, F. H. \& Mayne, P. W. (1990). Manual on estimating soil propertis for foundation desing. Electric Power Research Institute. Polo Alto, California.

\section{Contact information}

Neđo DJURIC, Prof. PhD of geology

(Corresponding author)

Technical Institute Bijeljina,

Starine Novaka 25, 76300 Bijeljina, Bosnia and Herzegovina

E-mail: nedjo@tehnicki-institut.com

Dijana DJURIC, M.Sc geographer

Universityof Novi Sad, Facultyof Civil Engineering Subotica,

Kozaračka 2a, 24000 Subotica, Serbia

E-mail: dijana.djuric.gf@gmail.com

Dragan LUKIC, Prof. PhD of Civil Engineering

Universityof Novi Sad, Facultyof Civil Engineering Subotica,

Kozaračka 2a, 24000 Subotica, Serbia

E-mail: drlukic.lukic@gmail.com 